\title{
Se

\section{Digital Humanities and Transdisciplinary Practice: Towards a Rigorous Conversation} lan Isemonger, Faculty of Letters and Graduate School of Social and Cultural Studies, Kumamoto University, Kurokami,
Kumamoto-shi, Japan, Email: ian-m@kumamoto-u.ac.jp

Received 15 June, 2018; Revised 17 August, 2018; Accepted August 25, 2018

Copyright (C)2018 lan Isemonger. This is an open access article distributed under the Creative Commons Attribution License (https://creativecommons.org/licenses/by/4.0/), which permits unrestricted use, distribution, and reproduction in any medium, provided the original work is properly cited.

Available online 30 August, 2018 at www.atlas-journal.org, doi: 10.22545/2018/00105

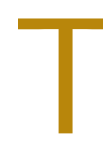

he digital humanities is frequently and casually associated with supradisciplinarity; either as multidisciplinarity, interdisciplinarity or transdisciplinarity. This paper endeavors to put digital humanities into a more rigorous and critical conversation with the three forms. Two broad approaches to distinguishing the three supradisciplinary forms are represented, namely, the definitional and theoretical approaches; with the latter emphasized as providing more analytical traction for a critical conversation with the digital humanities. In this regard, the Nicolescuian and Zurich schools of thought on supradisciplinary practice are elaborated with an emphasis on transdisciplinarity, and are identified with a priori and a posteriori theorization, respectively. Digital humanities and its ancestor, humanities computing, are analytically distinguished because the shift in name represents something substantive and consequential for the conversation. Overall, transdisciplinarity is amplified as of particular value for situating and theorizing the activities associated with the dig- ital humanities as part of a new knowledge condition.

Keywords: Digital humanities, DH, humanities computing, transdisciplinarity, interdisciplinarity, multidisciplinarity, supradisciplinarity, disciplinarity, transdisciplinary, interdisciplinary, supradisciplinary, epistemology, information abundance, academy, transformation

\section{Introduction}

Digital humanities is drawing increasing attention internationally after a period of significant initial growth in both activity and institutional representation in a part of the world which is perhaps best circumscribed as comprising the North Atlantic countries. The informal evidence for this rather rough but serviceable circumscription is readily available at, for example, the centerNet website (centerNet, [1]), where a map is available which indicates participating centers in different parts of the world, and where the distributions of these centers are heavily 
skewed toward Western Europe and North America. Africa and Asia, and some other parts of the world, seem to be taking note of these developments and the first signs of projects, societies and other professional apparatuses associated with the new area of inquiry are emerging. Similarly, interest in multidisciplinarity, interdisciplinarity, and transdisciplinarity, while having emerged in the traditionally dominant knowledge centers of the world is expanding into areas less so. These three forms of knowledge production, which are often highly situated in real-world problems, rather than in the extension of the disciplinarities for intrinsic disciplinary purposes, strike a particular chord with such areas; i.e. areas where the imperative for transformation of the material conditions and lives of people is pressing. The relatively contemporaneous expansion of both digital humanities and these three forms of knowledge production into new areas of the world is both significant and conspicuous, and intensifies the need for critical engagement with both. Such critical engagement inevitably turns to the question as to whether they serve each other in some way, or indeed, whether they may even be shared expressions of a similar phenomenon of intellectual transformation of the academy and its relationship to the wider society in which it is situated.

The area of inquiry called digital humanities is difficult to define and is in fact highly contested; famously or infamously, depending on one's disposition with respect to the merits and demerits of the problem. However, it can be usefully conceptualized as having initially emerged through the earlier field of humanities computing which it has now in fact absorbed, or superseded, and which sought to bring computational methods to bear on traditional humanities-type questions. Later, however, and associated with a discursive shift to the term "digital humanities" (Schreibman, Siemens, \& Unsworth, [2]; Svensson, [3]), there was a significant widening of field ${ }^{1}$ remit, along with a corresponding and significant loss of signal with respect to what the field actually was. This widening of remit seems to have comprised two threads. First, the influential book by Schreibman et al., associated with the shift to the new term "digital humanities," was also associated

\footnotetext{
${ }^{1} \mathrm{I}$ am going to continue to occasionally refer to digital humanities as a field for the purposes of this paper, but I recognize that this status is put into question by precisely some of the positions articulated in the paper.
}

with a shift from an exclusive interest in computational approaches to the humanities (i.e. humanities computing) to an additional, and somewhat inverted, interest in what the humanities might bring to the computational and digital (Hockey, [4]; Porsdam, [5]). Second, and more recently, digital humanities has come to include a following (e.g. Svensson, [6], [7]; Schnapp \& Presner, [8]) who see it as the site for transformation of the whole of the humanities and its place in wider society, and even as the place for a form of activism to this end. From across these areas, which represent a very rough guide to the field topography of current digital humanities, discontinuity with traditional disciplinary boundaries is frequently claimed for digital humanities and adjectives such as interdisciplinary, multidisciplinary and transdisciplinary are common descriptors for digital humanities activities, projects, centers, and the like. The relative lack of institutionalization of digital humanities as a discipline, and its rapidly accelerating institutionalization through hybrid centers, labs, institutes and so forth (Svensson, [9]), provides intuitive confirmation that this new area of inquiry is finding its place within the academy across the boundaries of the traditional disciplines rather than alongside them. However, it is important to recognize that these kinds of short-handed observations, while intuitively appealing and perhaps casually accurate, require deeper interrogation. For one thing, interdisciplinary, multidisciplinary and transdisciplinary do not mean the same thing, though they are frequently used interchangeably, and they require different thresholds and types of collaboration in each case; subject, of course, to the often contested positions on where these thresholds are, or, perhaps, should be stipulated to be. For another, an area of inquiry like digital humanities which is also distinguished by highly contested boundaries, does not, as a result of this contestation, offer an easy test for claims to being multidisciplinary, interdisciplinary or transdisciplinary. Things are more complicated and it is necessary to put digital humanities and these three forms of supradisciplinary status or activity into a more extended, rigorous and comprehensive dialog with each other.

The purpose of this paper is to offer an incremental step in this direction in advance of what may well be the significant and continued propagation of digital humanities and the three forms of supradisciplinary knowledge production, referred to 
as multidisciplinarity, interdisciplinarity and transdisciplinarity, into further reaches of the world. The approach taken to initiating this dialog is to isolate some important contributions to distinguishing the three forms, but emphasize two of them, namely, the contributions of Nicolescu [10], [11], [12], [13] (among many other contributions $)^{2}$ and the Nicolescuian approach, and the contributions of Gibbons et al. [14] and the Zurich approach; giving this paper, therefore, a primary focus on transdisciplinarity rather than the other two forms. Both of these contributions are notable for being highly theorized, and they provide, therefore, analytical traction, although I argue that Nicolescu's theorizing is more of the a priori variety, and Gibbons et al. is more of the a posteriori variety. With respect to digital humanities, the approach is to first, and briefly, consider the humanities computing legacy and its then posture with respect to the three forms of supradisciplinary status, and then discuss what the shift to the new name, digital humanities, means with particular respect to claims of transdisciplinarity; because this shift is actually more substantive than merely lexical. There are remarkable resonances between the rhetoric and ambitions of transdisciplinarity and humanities computing, and these resonances become more obvious as digital humanities succeeds to humanities computing. This is the case with both major approaches to transdisciplinarity; i.e. the Nicolescuian and Zurich approaches. With respect to the trends observed by Gibbons et al. [15], in particular, and associated with what they term Mode 2 knowledge production, this is so much so that one might consider digital humanities a further instantiation of their case.

\section{Approaches to Understanding Three Forms of Going Beyond Disciplinary Bounds}

To place digital humanities in a more explicit and rigorous dialog with the notions of multidisciplinarity, interdisciplinarity and transdisciplinarity, it is required that these three are distinguished; and also explicitly. To this end, it should be cautioned that

\footnotetext{
${ }^{2}$ Nicolescu has produced a large body of work on transdisciplinarity extending back to the mid-1980s. The works cited here are not intended to be comprehensive or representative, but are sufficient to the reporting of his main theorizing for the purposes of this paper.
}

distinguishing them here is more in the spirit of requirement for subsequent analyses than in the spirit of the protracted critical engagement which would ensue in an analysis of them for their own sake. Such protracted engagement is outside the scope of the paper, and it is acknowledged that different assumptions about what distinguish these three forms would place different contingencies on subsequent analyses. While this is limiting, it is also inevitable, in the same way that an essay on transdisciplinarity itself would have to engage and proceed with a notion of science not blind to, but also not hamstrung by, the demarcation issues which remain perpetually unresolved within the philosophy of science and other areas of metatheoretical conversation. However, it is important that the assumptions one proceeds with are relatively consistent with current consensus and are not extraordinary; and therefore not in need of extraordinary argumentation. It is also important to bear in mind, as Klein [16], [17] and Spaapen, Dijstelbloem and Wamlink [18] note, that research within the multidisciplinary, interdisciplinary and transdisciplinary context is too complex to treat as falling into discreet categories. However, while this acknowledgment of a complex reality on the part of these authors is apt, it should not chasten our natural intellectual proclivities to make distinctions which are helpful in imposing an at-least workable and provisional analytical order on the complexity.

Given these careful, but rather labored, qualifications, there are essentially two approaches to providing analytical order to these three forms of supradisciplinary activity. The first approach is definitional and is, therefore, essentially a form of stipulative order, though the stipulation is usually not arbitrary or critically uninformed, and may involve exemplars, elaboration and reflection on the literature. Two contributions which are associated with this approach are selected for this paper, namely, Rosenfeld [19] and Choi and Pak [20]. The advantage of both of these contributions is that they give coverage to all the three forms. The second approach to the problem of analytical order is to theorize the three forms of supradisciplinary activity, though, and in the work which thus far exemplifies this approach, this theorization may not be equally distributed across the three forms, or even be absent for some forms. The theorizing can take the form of a priori theorizing or a posteriori theorizing. In the case of $a$ priori theorizing, the work of Nicolescu [21], [22], [23], 
[24] and the school of thought which has emerged around his ideas is selected. In the case of a posteriori theorizing, the work of Gibbons et al. [25] and the associated Zurich school is selected. Nicolescu's work provides coverage to multidisciplinarity and interdisciplinarity but emphasizes transdisciplinarity. The work of Gibbons et al. essentially neglects multidisciplinarity and interdisciplinarity and provides extended coverage on what they term "Mode 2 knowledge production," which they explicitly align with transdisciplinarity. While Nicolescu's approach is more the theorization and advocacy of a system as a way out of a perceived dislocation in the human experience of the knowledge condition (thus a priori theorizing), the work offered by Gibbons et al. involves description and theoretical elaboration of what the authors, at the time, perceived as forms of knowledge practice already emerging and the gathering change they saw as associated with these practices (thus a posteriori theorizing). The contributions from both Nicolescu and Gibbons et al. are of particular importance with respect to transdisciplinarity which is the main focus of this paper. McGregor [26], [27], for example, has made a clear distinction, informed by the earlier work of Klein [28], between the Nicolescuian and Zurich schools of transdisciplinarity; schools which are informed by these two contributions respectively ${ }^{3}$. The distinction between these two schools is important in putting transdisciplinarity into comprehensive and analytically substantive dialog with digital humanities, because, while both are expressions of the transdisciplinary movement, they are also advanced via a different rationale. Gibbons et al. are not so much articulating a new system from ground up, as giving vital a posteriori theoretical expression to a system they perceive as already under construction and as emergent. Here the state of affairs they perceive in the world precedes the imagination. Nicolescu, on the other hand, appears to be engaged in an endeavor to clear a way for something which he sees as

\footnotetext{
${ }^{3}$ While the Zurich school is traditionally cited as emanating from an international congress in Zurich, Switzerland, in March 2000, many of the contributions were deeply informed by the book entitled "The new production of knowledge: The dynamics of science and research in contemporary societies," published by Sage in 1994 in London. The proceedings for the conference are available in a book by Klein et al. titled "Transdisciplinarity: Joint problem solving among science, technology, and society," and published by Birkhäuser Verlag in 2001.
}

vital, by providing a priori theorization for it. Here the imagination is exercised for a desired state of affairs in the world.

Turning first to definitional approaches and to Rosenfeld [29], the analytical separation of these three supradisciplinary efforts was offered in the context of health care and as a simple taxonomy of cross-disciplinary ${ }^{4}$ research (Table 3, p. 1351) and is quite widely cited. The following definitions are presented:

\section{Level One: Multidisciplinary}

Researchers work in parallel or sequentially from disciplinary-specific base to address common problem.

\section{Level Two: Interdisciplinary}

Researchers work jointly but still from disciplinary-specific basis to address common problem.

\section{Level Three: Transdisciplinary}

Researchers work jointly using shared conceptual framework drawing together disciplinary-specific theories, concepts, and approaches to address common problem. (p. 1351)

With regard to multidisciplinarity, Rosenfeld cites this form as the most common and notes that results are brought together at the end of separate attention to the same problem. Interdisciplinarity involves joint work on the same problem, and superior insights emerge from this, but Rosenfeld argues that the results are then usually handled separately with this separation being discipline-based. The central contribution of Rosenfeld's paper was to explicate the third form, transdisciplinarity, as going completely beyond the limitations of the first two, and a project in Brazil related to malaria in migrant populations is cited as being an exemplar of an approach in line with this third form. She claims that in terms of this form, the "[r]epresentatives of different disciplines are encouraged to transcend their separate conceptual, theoretical and methodological orienta-

\footnotetext{
"The term "cross-disciplinary" is used by Rosenfeld as a generic grouping term for the three versions of supradisciplinary activity, namely multidisciplinarity, interdisciplinarity and transdisciplinarity. It should be noted, however, that cross-disciplinarity is sometimes treated as a fourth category on the same order of taxonomy as the other three mentioned, although it is not treated as such in this paper.
} 
tions in order to develop a shared approach to the research, building on a common conceptual framework" (p. 1351). There is something of an order between these three forms with level two exceeding level one in integration, and level three exceeding level two. However, while it is intuitively satisfying to simply see these three levels as representing an ordinal scale of increasing integration, the third is in fact quite different, or so it is explained. The word "transcend" denotes that the integration is more than the sum of the parts or, put another way, more than intensified aggregate activity. Rather, it is something with emergent properties where the product is qualitatively distinguishable from the constituent inputs. This is a notion of transdisciplinarity which frequently appears across a variety of texts engaged with it in one way or another. One notable aspect of Rosenfeld's articulation of transdisciplinarity is that it is largely situated around the person; i.e. around sociologists, epidemiologists, economists, anthropologists and so forth, rather than around sociology, epidemiology, economics, anthropology and so forth This is perhaps the consequence of the study being case-study led with something of a show-and-tell rationale, which is not a criticism, but rather a description of it. However, it does amplify the fact that transdisciplinarity is essentially undertheorized in this notable contribution.

Still with the definitional approach, Choi and Pak [30] proceed in a different way and provide coverage of all three forms, by taking a rigorous attitude to sampling the definitions people are giving to them, and then endorsing one definition for each form. There are some limitations to this kind of authority, however. First, while language is a rule-governed activity and such analyses give air to common use, and the rules people place themselves under when they use words and intend to mean something, people can follow such rules either intermittently or in an ill-disciplined way; especially people outside the specialist or invested core. Second, the use of this kind of source is helpful in grounding our understandings in necessary attention to the wider norm, and testing the potential parochialism of the invested core in how the term is used, but it should also not end up as analytical reduction to populism. Essentially, theorization is always better. Third, it is the methodology employed which confers the rigor, and this needs a critical eye. For example, Choi and Pak use three sources for their analysis: dictionaries, Google searches and MEDLINE searches. The first source, dictionaries, should be treated with considerable circumspection because dictionaries are essentially linguistic aids when looking for a first-time definition of a new word, and while the definitions offered may have a survey-based grounding, confirming such, as well as finding out how such was conducted, is difficult for specific terms, and the issue is essentially opaque. This is not to mention the problem of circularity in turning to a book of definitions to provide evidence for the stipulation of a definition.

The limitations with respect to dictionaries is reflected in the final analysis where Choi and Pak [31] state that "these terms [multidisciplinarity, interdisciplinarity and transdisciplinarity] are found to be relatively new, poorly differentiated even in dictionaries, confusing and often used interchangeably among many authors, but starting to converge or 'gel' towards certain specific meanings" (p. 359, my italics). The lack of differentiation in dictionaries will naturally reflect contestation and diversity in the wider corpus, because dictionaries are authored to reflect the wider corpus without bias; and this has to be achieved while remaining concise. Thus we have definitions, among others, like "[r]elating to more than one branch of knowledge" for interdisciplinarity (cited from the Compact Oxford English Dictionary, 2005, by Choi \& Pak, [32]); a definition which is conspicuous only for being rather vague. Choi and Pak's data, however, becomes more illuminating when the online literature (Google search) and peer-reviewed literature (MEDLINE search) are referenced (see Table 1 and Table 2, Choi \& Pak, [33], pp. 353-356). In the definitions for multidisciplinarity, the numerical issue of there being more than one discipline involved is obviously present, but so are notions of participants maintaining separation present; similar to Rosenfeld [34] above. This separation, according to the data, is expressed variably as, for example, working independently, maintaining disciplinary roles, not challenging disciplinary boundaries, working in parallel and so forth. In the definitions for interdisciplinarity, this separation becomes attenuated to some degree or another. We see references in the data to working together, reciprocal action, common roles, blurring of disciplinary boundaries and the like. My qualifier "to some degree or another" is the operative issue here, because some references with respect to interdisciplinarity attenuate on the low side, indicating only some surrender 
of disciplinary boundaries, while others attenuate on the high side, indicating as much as the possibility of new fields emerging, consistent with Nicolescu's view of this form [35] (see below). Some on the high side also refer to the whole being more than the sum of the parts. The Gestalt analogy would not be consistent with Rosenfeld [36], and arguably not consistent with Nicolescu [37] either. The Gestalt analogy is invoked to capture a qualitative shift beyond the constituent elements, or to capture emergent properties, but, this is usually reserved for transdisciplinarity (see below for further discussion), and certainly in Nicolescu's case it is. Its presence in the data here for interdisciplinarity is perhaps anomalous, or reflects the permeable boundaries of the common application of these terms. In the definitions for transdisciplinarity, as one would expect, the notion of going beyond boundaries is frequently invoked, and this is more unequivocal than is the case for the definitions of interdisciplinarity. One of the definitions emphasizes role release and role expansion (Kessler, [38]) while, importantly, others indicate collaboration beyond the academy altogether, involving stakeholders (Common \& Stagl, [39]), non-scientists (Flinterman, Teclemariam-Mesbah, Broerse, \& Bunders, [40]), and non-academics (Tress, Tress, \& Fry, [41]), which is consistent with Gibbons et al. [42] (see discussion below) and Mode 2 knowledge produced at the site of application.

Choi and Pak [43] (p. 359), prefer not to synthesize the convergences in these definitions, but rather to propose definitions based on a specific citation, or one particular case. The following are the definitions they recommend with their cited source for the definition in each case:

Multidisciplinarity draws on knowledge from different disciplines but stays within the boundaries of those fields (NSERC, [44]);

Interdisciplinarity analyzes, synthesizes and harmonizes links between disciplines into a coordinated and coherent whole (CIHR, [45]);

Transdisciplinarity integrates the natural, social and health sciences in a humanities context, and in so doing transcends each of their traditional boundaries (Soskolne, [46]).

Notably, the first two definitions come from defini- tions offered in guideline-type literature associated with research grants. With respect to multidisciplinarity, the proposed definition is relatively consistent with Rosenfeld [47], and this seems to contribute to a wider picture where the definition of multidisciplinarity is the least contested of the three. With respect to interdisciplinarity and transdisciplinarity, the definitions are less distinguishable, and though selected and endorsed by the authors, do not seem to rescue notional aspects emerging in the rest of their data; although they do discuss these other notional aspects late in the paper. However, in terms of the endorsed definitions, it is clear that transdisciplinarity expresses some convergence between the sciences and humanities which interdisciplinarity does not. A position explicitly adopted by Choi and Pak, which is not necessarily comfortable with either the Nicolescuian or Zurich schools (see below), is that they recommend that the three forms "be used to describe multiple disciplinary approaches to varying degrees on the same continuum" (p. 359); whereas the Nicolescuian or Zurich schools would want to retain a distinction of category, rather than degree, for the third form, namely transdisciplinarity.

The lack of theorizing in the Rosenfeld [48] and Choi and Pak [49] account of the three forms of supradisciplinary activity, particularly with respect to transdisciplinarity, or the third form, turns the discussion over quite aptly to the contribution which comes from Nicolescu [50], [51], [52], [53]. This work is conspicuous for its theorizing, though multidisciplinarity and interdisciplinarity are relatively less theorized than transdisciplinarity. The first two are, in fact, more the background put in service to the foreground which is transdisciplinarity, and this third category is highly theorized. Nicolescu [54] states that "[m]ultidisciplinarity concerns studying a research topic not in just one discipline but in several at the same time" (p. 6). Note the correspondence here with the definition offered by Rosenfeld and, indeed, the data appearing in Choi and Pak. Multidisciplinarity presents as the least contested form overall. Nicolescu's [55] account of interdisciplinarity, however, is more developed than that of Rosenfeld, and he states that it "has a different goal than multidisciplinarity," and "[it] concerns the transfer of methods from one discipline to another" (p. 6). He goes on to distinguish three degrees of interdisciplinarity, namely, the degree of application, the degree of epistemology, and the degree of generation 
of new disciplines. Both the rather straightforward characterization of interdisciplinarity and the distinction between the three degrees are analytically useful later in this paper with respect to humanities computing, the progenitor of digital humanities. The major part of Nicolescu's contribution, however, is reserved for the theorizing of transdisciplinarity, or the third form.

Nicolescu [56] argues that three essential foundations underpin transdisciplinarity, and these foundations are articulated under the categories of the epistemological, the ontological and the logical. With respect to the epistemological, the central claim here is that knowledge is emergent and complex. Here, classical notions of a unidimensional but complex reality being reduced to simpler laws, according to the principle of parsimony and under the laws of determinism, are eschewed by Nicolescu for a perspective which embraces complexity. I think it is probably important to point out here that Nicolescu would reject these notions associated with classic thought only for transdisciplinary practice, and not necessarily for disciplinary practice alongside which transdisciplinarity is construed as complementary rather than competitive; or at least this is my reading (Nicolescu [57], p. 7; [58], p. 22). Importantly, the classical perspective is linear, in line with determinism and cause and effect, and this will resonate later because digital humanities, like transdisciplinarity, appears to test this sort of epistemological inheritance. With respect to the ontological, Nicolescu theorizes, or perhaps metatheorizes, that there are multiple levels of Reality ${ }^{5}$ separated into three levels, with the first two levels representing the internal (TD-Subject) and external (TD-Object) worlds, respectively. These two levels are mediated by what he terms the Hidden Third; essentially a theoretical device to bridge an undesirable radical separation between the subject and object of knowledge. The notion of the Hidden Third is articulated, perhaps not so much as the space between, but as the meet-

\footnotetext{
${ }^{5}$ Certain terms are presented by Nicolescu as proper nouns (first letter capitalized) to distinguish them from more routine use and as central concepts to his system of thought. The word reality, for example, even in everyday use, is bound up with classical ideas of reality being unidimensional and external to the subject; and discoverable by appropriate means. Given that Nicolescu's ontological position eschews such classical views of what reality is, and advocates multiple levels of reality, he chooses to nominalize his theory of reality via the proper noun. He does this for other theoretical constructs too.
}

ing point between the first two levels and constitutes a zone of "non-resistance" where seemingly irreconcilable inputs become reconcilable, at least provisionally, and function as the source of new knowledge. This separation bridged by the Hidden Third is, of course, associated with classical thought, and Nicolescu sees this as very much the problem with the human knowledge condition, and the origin of the dislocation between the sciences and the humanities. His position on this represents an attempt to open up theoretical space for the mediation of apparently competing world views, and this, naturally, is the anvil on which transdisciplinarity, given its mission to transcendence of aggregate disciplinary inputs, will either be forged or not forged. Much of what is in his theoretical positon on this is inspired by Nicolescu's engagement with, and background in, quantum physics and the rather extraordinary questions this branch of knowledge asks of our inherited epistemologies (Nicolescu, [59]). With respect to the logical, Nicolescu makes the case for what he terms "inclusive logic," as opposed to the exclusive logic of classical thought; and this is also referred to as the Included Middle. This aspect of his theorizing is also related to reconciling the perceived gulf between the sciences and the humane.

Nicolescu's work, which is much of the foundation and outlook for the wider Nicolescuian approach to transdisciplinarity, is juxtaposed to the Zurich approach, which is viewed as more practical ${ }^{6}$ in nature and as being in alignment with, and born out of, Gibbons et al. [60] and their outlook for transdisciplinarity; with Gibbons et al. being the second theorized contribution of interest for this paper. As stated earlier, the work of Gibbons et al. is more descriptive and exploratory of states of practice which the authors deem to be incipient, but gathering, and therefore as indicative of a course of change for the future. Their contribution is not explicitly averse to the a priori theorizing of Nicolescu as a form of intervention, but it does explicitly present as something different; i.e. as description and a posteriori theoretical elaboration of the contours of perceived trends, already underway and requiring of our collective comprehension. This is clear as early as in the first paragraph of the introduction to their work:

This volume is devoted to exploring

\footnotetext{
${ }^{6}$ Nicolescu himself characterizes the Zurich approach as phenomenological; as opposed to his own approach which he describes as theoretical.
} 
changes in the mode of knowledge production in contemporary society. Its scope is broad, concerned with the social sciences and the humanities as well as with science and technology, though fewer pages are given to the former than the latter. A number of attributes have been identified which suggest that the way in which knowledge is being produced is beginning to change. To the extent that these attributes occur across a wide range of scientific and scholarly activity, and persist through time they may be said to constitute trends in the way knowledge is produced. No judgement is made as to the value of these trends-that is, whether they are good and to be encouraged, or bad and resisted-but it does appear that they occur most frequently in those areas which currently define the frontier and among those who are regarded as leaders in their various fields. (Gibbons et al., [61], p. 1)

Notably, the presentation of these descriptions is claimed to be value-free, although there is some form of, perhaps, implicit endorsement by the identification of the drivers of this change with the leaders of respective fields. This is unlike Nicolescu where values are arguably not central to the theorizing, but are clearly very important to them, because the theoretical intervention on the whole is offered very much in assistance to challenging the notion of a value-free science in a state of dislocation from the humane. It should also be added with respect to the Gibbons et al. work that, while descriptive, it is not low-level description. They construct a vision through their characterizing of the described trends and changes, and they give extended and conceptual expression to these as well. I would characterize this, as I said, as a posteriori theoretical elaboration of the descriptive case.

The contribution from Gibbons et al. [62] is expounded around a primary distinction between Mode 1 and Mode 2 forms of knowledge production. These labels are semantically featureless, perhaps in tune with the value-free aspirations of the work, but are intended to distinguish a traditional mode of knowledge production (Mode 1) aligned with customary disciplinarity and a new mode of knowledge production (Mode 2) aligned with something which could be said to exceed disciplinarity, and indeed the academy itself. The authors associate Mode 1 knowledge production with the diffusion of the Newtonian model of doing science (note, this does not mean the Newtonian model of physics) into an increasing number of areas of inquiry. This model emphasizes disciplinarity through legitimization of what does and does not count as science, and via norms and methods and so forth which are foundational to this legitimization; with these being enforced by the discipline and for the benefit of the discipline. Also, knowledge production in this mode is essentially linear; though one assumes some kind of qualification here surrounding scientific revolutions and disruption. The important distinction with regard to Mode 2 knowledge production is that it does not represent a relaxation of the rules for Mode 1, or their simple neglect, but rather a newly-constituting set of practices which occur in the context of heterogeneity and application; application here implying that activities are also problem-focused rather than discipline focused. Both modes exhibit different forms of control. Mode 1 exhibits a control system which is hierarchical and preserved, while Mode 2 exhibits a system which is heterachical and transient (p. 3). Importantly, for later analyses with respect to digital humanities, the authors see Mode 2 as more reflexive than linear and more socially situated and accountable. Linearity is also particularly important with respect to the process of disseminating knowledge, because in Mode 1 dissemination is so, i.e. linear, and this is achieved by the still-familiar institutional channels of journals and conferences and so forth, gate-kept by the disciplinary community for the furthering of disciplinary knowledge gains. In Mode 2 knowledge production, this linearity of knowledge dissemination is replaced by a model associated with the site of application. As Gibbons et al. put it, "diffusion occurs primarily as the original practitioners move to new problem contexts rather than through reporting results in professional journals or at conferences" (p. 5 ). Thus, what we have here are knowledge practices not detached from the disciplines and the knowledge produced there, but also not structured by them and also growing in presence relative to them. These practices are more firmly embedded in the wider social fabric, more transient, more situated in application, and more responsive to concerns which exceed the narrow concerns of disciplinary gains; and they are generative of new forms of knowledge as a result. 
In reflection of the above two theoretical approaches to transdisciplinarity, it should be said that, for some, the theorizing of Nicolescu seems quite remote from the everyday experience and practice of knowledge creation. Bernstein [63], for example, while referring to Nicolescu's insights as "bold and visionary" (para. 11), has also characterized the theoretical framework as "abstruse" (para. 11) and the work in general as "programmatic and oracular" (para. 11). The Zurich approach, on the other hand, grounded in practices consistent with Mode 2 knowledge production and the work of Gibbons et al. [64], while arguably offering more tangible and proximate moorings for the researcher pondering a shifting ecology of knowledge production, is also open to charges of being undertheorized, and in fact, being not too different from action research. Action research after all is quintessentially problem focused and context-rooted, or situated in application, and while not without theorizing in the problem solving process, the action research process itself is generally not theorized far beyond the typical schematics used in textbooks to represent the cycles of such research. Nicolescu [65] himself has stated that the Zurich approach, citing Michael Gibbons and Helga Nowotny (two of the authors of Gibbons et al. which has six authors), is "characterized by the refusal of formulating any methodology and by its exclusive concentration on joint problem-solving of problems pertaining to the science-technology-society triad" (p. 144). Here I would read Nicolescu's emphasis on absence of methodology as also emphasizing absence of theory, because to have method one has to have theory. It is not my intention to wade into the merits and demerits of either case here, because this would rob the issue of the discursive scope it deserves. Suffice to state, there is plenty from both schools here which resonates with aspects of digital humanities inquiry, and the type of role it is either acquiring, or seeking to acquire, within and beyond the academy.

Overall, and in view of the four main contributions discussed above, we are left with the following picture of the three forms of supradisciplinary practice. Multidisciplinary practice is the least contested form of the three, and is generally identified with work on a common problem across the disciplines, but with disciplinary separation intact. This is the case for the definitions (Choi \& Pak [66], p. 353, [67], p. 354; Rosenfeld, [68]), and for Nicolescu's
[69] explanation of it. Interdisciplinary practice is generally expressed with some attenuation of the separation of disciplines, but the level of attenuation can vary. On the low side, this attenuation would involve some integration of approach while maintaining disciplinary identity, and on the high side, this attenuation may be as much as the formation of new disciplines. Nicolescu's explanation and theorization of it explicitly includes this possibility, via his notion of the degree of formation of new disciplines, and some of the data from Choi and Pak reflects this possibility too. Nicolescu's theorizing of interdisciplinarity also includes the degree of epistemology and degree of application which are analytically useful theoretical elaborations of the interdisciplinary case, and especially with regard to digital humanities and its forerunner, humanities computing (see below). Transdisciplinary practice is generally expressed as categorically distinct from the first two forms, and this is reflected in the definitional approaches covered (Choi \& Pak, [70]; Rosenfeld, [71]). Two schools of theorized thought feature strongly in our current comprehension of what it is, and both would also support its categorical distinction from the first two forms, namely multidisciplinarity and interdisciplinarity. While not incommensurate, these two schools proceed under the quite different rationale of a priori theorizing and a posteriori theorizing, as covered above. Nonetheless, and as will be elaborated below, both have much to offer in putting transdisciplinarity into a more rigorous dialog with digital humanities.

\section{Digital Humanities and Disciplinary Discontinuity}

Defining digital humanities may be a contested issue, and an issue which receives no shortage of discussion in the literature (Kirschenbaum, [72]), but about its origins in the earlier constituted area of inquiry called humanities computing there is little debate. Hockey [73], who was writing in the edited volume titled $A$ Companion to Digital Humanities (edited by Susan Schreibman, Ray Siemens and John Unsworth), a text which was to become widely associated with the discursive shift (Svensson, [74]) from the term humanities computing to the term digital humanities ${ }^{7}$

\footnotetext{
${ }^{7}$ The account given for the rise of the term digital humanities can be found in Fitzpatrick's article titled "The humanities
} 
in the mid-2000s, provides a useful history of humanities computing. The deepest roots of humanities computing, like those of corpus linguistics, are cited as beginning with the work of Father Roberto Busa, an Italian Jesuit priest, in 1949, who lemmatized the works of Saint Thomas Aquinas, building an index of all the words contained in the works, in a project which took many years, and marked the first attempt to take a quantitative approach to text assisted by computation. What followed from this was a realization that computation allowed for a quantitative approach to style and authorship (Hockey, [75]), and what subsequently unfolded from this was a long trajectory of building the tools and protocols to do this successfully (Fitzpatrick, [76]). While computation heralded great opportunities, realizing the opportunities involved a long and hard technical slog by dedicated people. Standards and protocols were required for the encoding and treatment of text to ensure compatibility and efficiency. It is outside the scope of this paper to document this (see Hockey for a fuller account), but one project stands out for enabling such work, and it is also useful for exemplifications later in this analysis. After a period of consolidation in encoding, character sets, storage and retrieval from the 1970s to the mid-1980s (Hockey, [77]), one of the most significant contributions to the project of normalizing and standardizing text encoding was the Text Encoding Initiative (Burnard, [78]; Hockey, [79]; see TEI P5: Guidelines, [80], for latest version) which was first published in 1994 The initiative emerged out of the publication of the Standard Generalized Markup Language (SGML) by ISO, and as Hockey notes, it was "a markup scheme that could handle many different types of text, could deal with metadata as well as data, and could represent complex scholarly interpretation as well as the basic structural features of documents" (para. 36). She highlights this initiative above all other accomplishments in the long process of creat-

\footnotetext{
done digitally," appearing in the edited volume "Debates in the digital humanities," and published by the University of Minnesota Press. The same account can also be found in another article of the same volume by Kirschenbaum. The account goes that Susan Schreibman, Ray Siemens, and John Unsworth were discussing a potential volume with Blackwell publishing in 2001 which was to be titled "A Companion to Humanities Computing." Because the publishers wanted a book with wider appeal the title "Digitized Humanities" was considered before Unsworth proposed "Digital Humanities," apparently to avoid the field being perceived as only about digitization.
}

ing the technical systems for humanities computing to thrive, and remarks on the presence of one of the main contributors, Michael Sperberg-McQueen, as the future co-editor of the XML markup standard. The emergence of the TEI out of the impact of SGML, and then the migration of competency from the TEI into the next-generation XML, represents notable crossover between the academy in general, humanities in particular, and the wider computing industry.

Of this humanities computing legacy, there are some features which are important to abstract in advance of moving on to discuss the discursive or lexical shift to the term "digital humanities," along with the associated expansion of remit. The first, and perhaps most important, is that humanities computing very much involved transfer, in a largely unidirectional way, of two things, namely, method and technology. The second is that the object of engagement for these methods and technologies was primarily, though not exclusively, text (Burdick, Drucker, Lunenfeld, Presner, \& Schnapp, [81]; Schnapp \& Presner, [82]). With respect to the first, i.e. transfer of method, we are talking here about quantitative and algorithmic approaches to the analysis of text associated with what is referred to as the distant reading (Moretti, [83]). Here the close, highly interpretive, and reflective reading of traditional scholarship is forfeited for, or triangulated with, a more distributed and detached approach to the text; which it should be said is not without interpretation, only the interpretation is quantitatively grounded and more explicitly evidence-based. In terms of technology transfer, computation is the issue, and this transfer is not unlike the impact that computation has had on any number of other fields. Even the social sciences-which had embraced the quantitative methods and epistemologies associated with the natural sciences before the humanities-were further empowered by computation through being able to cope with much larger datasets and perform statistical analyses which involved forms of statistical estimation not viable otherwise; a perfect example here would be factor analysis for which the principles were understood a long time before it was practically feasible to routinely perform such. On the second important issue in the humanities computing legacy, namely, the primacy of text, Burdick et al. remark that "the initial waves of computational humanities concentrated on everything from word frequency studies 
and textual analysis (classification systems, mark-up, encoding) to hypertext editing and textual database construction" (p. 122). In terms of this view, it is notable that text presented as a relatively stable and contiguous object of knowledge for both humanities computing and the traditional forms of scholarship in the humanities. This is important because within the humanities computing legacy what we are seeing, in general, is a transfer of methods and technology to the same knowledge object; or new methods for old problems so to speak. What is also important to recognize overall is that these new methods were not, and still are not, used simply to make traditional interpretation faster and more efficient, but rather they are adopted because they offer new eyes (McCarty, [84]) to the same object, and these are the macro-eyes of scale or distant reading; eyes not available to traditional reflective scholarship.

In the event of these abstractions, which I realize involve some simplification or rounding off, how do we place humanities computing, the progenitor to, and still vital component of, the digital humanities of today, in the context of the three forms of supradisciplinary activity? It is clear that Rosenfeld's definitions offer little analytical traction here for being centered on the person. All three definitions are constructed so as to require personnel from diverse disciplines working in some form of tandem, and while there might clearly be cases of personnel from the computer sciences in the centers which represented humanities computing into the 2000s, as well as clear cases of diverse personnel in flagship projects such as the TEI, the transfer of methods and the buildup of competencies for the humanities were clearly led by humanities scholars for the humanities. It was not so much personnel who were being transferred as methods and technology and the knowing how ${ }^{8}$, and personnel here are agents in this, but not the substantive issue. In terms of Choi and Pak [85], the definitions endorsed, rather than the data itself, are also not particularly helpful, because humanities computing seems to exceed the endorsed definitions of multidisciplinarity, which of course is fine, and resonate slightly with both interdisciplinarity and transdisciplinarity, but

\footnotetext{
${ }^{8}$ There seems to be an inherent analytical limitation in situating any formal construction of the three forms of supradisciplinary activity around the person, and perhaps this needs to be read as an overall limitation of Rosenfeld's definitions.
}

nonetheless, still has important incongruences with both. For example, and to remind the reader, the definition for transdisciplinary practice states that it "integrates the natural, social and health sciences in a humanities context" (Choi \& Pak, [86] p. 359; definition taken from Soskolne, [87]), but humanities computing is really the direct inverse of this. It represents the integration of traditional humanities-type questions and problems, usually with respect to text, into the methods associated with the sciences and computation; with these methods being, for example, things like encoding and quantification followed by the probabilistic reasoning of statistical inference.

If we turn to Nicolescu's theorizing, however, while his [88] (p. 6) notion of multidisciplinarity is probably asymmetric with humanities computing because text is not simultaneously being studied in multiple disciplines, his notion of interdisciplinarity, as involving the transfer of method, is particularly apposite. Furthermore, his elaboration of interdisciplinarity in terms of the degree of application, the epistemological degree, and the degree of generation of new disciplines, offers further analytical purchase. The degree of application is arguably represented in, for example, the use of humanities computing in the evidence-based and statistically inferential approaches to literary forensics or authorship studies (Craig, [89]; Hockey, [90]); not to mention that many of the projects are about the application of new methods and technologies (building essentially) for a new means to engage with text. Furthermore, if one draws on the notion of the methodological commons elaborated, in a highly influential article, by McCarty [91], the idea of application resonates quite strongly. McCarty, assisted by a schematic which is now frequently reproduced in conference presentations and so on (McCarty, [92], Fig. 1, p 1225), represents the methodological commons as a sub-tier of methodological competencies to the traditional disciplines, with these methodological competencies flowing out of the commons to these disciplines, and importantly back in again and then to others. Humanities computing he suggests is the interdisciplinary agency facilitating this trade in methodological competencies "in its dual role as collegial service to the disciplines and as research enterprise directed to investigate their evolving methodologies, devise new computational approaches, study the effects, and tease out the implications" (p. 1224). Importantly, we can construe this as agency for application, just as much 
as agency for methodologies, and in both cases we have something which aligns quite convincingly with Nicolescu's understanding of interdisciplinarity. Below the methodological commons is a further tier which comprises areas of inquiry which humanities computing draws on and these include, among many others, epistemology, ontology, linguistics, historiography, ethnography and so on. By this conception, the agent is theoretically informed but not a primary producer of theory as such; rather it is vehicle for methods in the degree of application which leverage the capacity to generate new knowledge via new lenses.

With respect to Nicolescu's epistemological degree, the position of humanities computing is significant for working at the interface of different or even rival epistemologies. While neither the close reading nor the distant reading has any privileged claim to engagement with justified belief on the basis of either synthetic or analytic truth, humanities computing's engagement with synthetic truth observes rules which are not frequently seen in traditional scholarship. These are the rules associated with the natural and social sciences, but transferred to the objective of connecting scholarly propositions to the world, usually the world of the text, under an evidence-based agenda. Included in this are things like explicit declaration of what is to be processed, explicit measurement, the probabilistic reasoning of statistical inference, replication and so forth. Essentially this is a form of empiricism, though not a naive form bereft of theory and interpretation. In this there is a transfer of epistemology from the natural sciences and social sciences to the humanities in line with Nicolescu's notion of the epistemological degree, but importantly this is not transfer to replace the epistemology of the close reading but transfer to augment the close reading. This augmentation can take the form of highly iterative practices of exchange between the close reading and the distant reading. This can occur even in the early stages of analysis where close reading, for example, might conceptually inform the basis for an appropriate structure and taxonomy of metalanguage to describe and measure a style in a text being prepared for the distant reading, and, in turn, the results which emerge out of this might inform another iteration of close reading. The point here is that the two epistemologies, which humanities computing sits in interface with, are not left in a state of unresolved interface, permanently faced off as discrete and rival epistemologies, but rather are knitted together in iterative and fine-grained interaction.

Nicolescu's notion of the degree of generation of new disciplines is analytically critical, because, and conspicuously so, humanities computing, and indeed its successor digital humanities, have not emerged as disciplines which Nicolescu indicates as possible under interdisciplinary practice; and though I am not sure he says this, I would presume the emergence of new disciplines to be the most extended form of interdisciplinary practice under his theoretical conception of it. There are two ways to interpret this for not having happened in humanities computing. First, and more negatively, humanities computing is in some way insufficiently coherent in its interdisciplinary practices to emergence, as itself, a new discipline. Second, and more positively, and indeed more thought-provokingly, it shares characteristics with transdisciplinary practice, i.e. as complimentary to the disciplines (Nicolescu, [93]; [94]), and as site for the generation of new forms of knowledge. The question as to whether humanities computing is a discipline has been an issue in the past (Burnard, [95]) with the absence of consensus being notable, and certainly McCarty's [96] notion of humanities computing as agent for the methodological commons configures this agency as permanently complimentary to the disciplines; thus lending a vision for the status of activities and practices in humanities computing as being more transdisciplinary than interdisciplinary. In terms of Nicolescu's position, we may have to be more guarded in assertions to transdisciplinarity over interdisciplinarity, because, and as covered above, there are also features of humanities computing which align strikingly with his explication of interdisciplinarity rather than transdisciplinarity, i.e. in terms of method transfer and so on. But, presuming that the resistance of humanities computing to emergence as a discipline is because of something other than an insufficiency, we are really invited to at least consider that it has transdisciplinary characteristics or properties for this. Also, the continuing lack of consensus around the status of digital humanities as a field, let alone a discipline, has become amplified, if anything, with some constituencies in the literature even viewing it as a force, at large, for transformation of the academy rather than a contender for a place in it (Schnapp \& Presner, [97]; Svensson, [98], [99]; see discussion below 
on the lexical shift to digital humanities). As stated immediately above-and it is worth stating it again because this is a vital issue which deserves analysis and engagement beyond this paper-the question here is whether this failure to emerge as a discipline is for neglect of trying, which I would suggest it is probably not, or whether there is something native to the practices which render them permanently incompatible with disciplinary status and leaning towards transdisciplinary status.

Nicolescu's notion of the degree of application is analytically important, but it is notable that the issue of application features just as strongly in the outlook of Gibbons et al. [100]; and not with respect to interdisciplinarity, but rather with respect to transdisciplinarity which they explicitly associate with their notion of Mode 2 knowledge production. Thus application is given a primary theoretical position as the foundation for the production of transdisciplinary knowledge. Humanities computing, as agent for the methodological commons and the trade in methods, is clearly envisaged by McCarty as activity embedded in application. It is not the primary driver of disciplinary theory, but rather is informed by theory from the areas of inquiry represented as underpinning it (the bottom tier of the schematic model), and its main role is in application, and primarily, but not exclusively, application of methods deeply informed by digitization, computation and quantification. However, and critically, this application is generative of new forms of knowledge. These forms would not be producible by traditional disciplinary scholarship involving the close reading, and yet this knowledge does feed back into disciplinary theory and interpretation. Also, and importantly, this trade with the disciplines is not linear or unidirectional. Because methods are exported from the commons to the disciplines, then back into the commons and then on again to others, while being of course transformed and reconfigured in this process, humanities computing represents a form of interface for migratory practices on the lower bound and interface for highly innovative practices on the upper bound, with these practices being predominantly situated in application. The long legacy of humanities computing is highly connected with building (Ramsay \& Rockwell, [101]) whether this be the building of the tools and protocols for the trade itself, or the building of applications on the basis of these tools and protocols. Furthermore, this building often occurs in interfaces with technologies and agencies emerging from outside the academy consistent with Gibbons et al. [102] and their notion of socially distributed knowledge production ( $\mathrm{p}$. 4) where supply and demand operates, but under the qualification that this supply and demand is diverse and has gone beyond the commercial market. McCarty's notion of humanities computing as agent in "this import/export trade" (McCarty, [103] p. 1224) of methods and techniques resonates strikingly with Gibbons et al. [104] and their notion of Mode 2 knowledge production; and so much so, that one might represent humanities computing as an important instantiation of their case, and that as such the trend is for such knowledge practices to increasingly define our world. Even the rhetoric of "trade," "import and export," and "supply and demand" corresponds with the conceptions offered by McCarty and Gibbons et al.

To continue the focus here, and to return to the quotation provided earlier, Gibbons et al. [105] (p. 5 ) identify Mode 2 knowledge transmission as associated with movement from context-bound problem to context-bound problem, with these contexts being diverse and fluid, and this is unlike traditional disciplinarity associated with linear knowledge production and linear knowledge dissemination in the discipline-restricted publishing process. The diffusion of knowledge in Mode 2 occurs in the process of production and later through the movement of practitioners from one problem context to another, and these contexts are transient. If one turns to important accomplishments of the humanities computing legacy, and taking the TEI as example once again, this project quite conspicuously represents the production of knowledge in the context of application; i.e. application of methods from linguistics, computer science and other fields to a problem, namely, the problem of describing text in a metalanguage to render it retrievable and processable for ulterior research and scholarly purposes ${ }^{9}$. Furthermore, the migration of key practitioners and devel-

\footnotetext{
${ }^{9}$ There is a case of course that encoding protocols are rules and not knowledge, but this would thoroughly neglect the case that the building of explicit metalanguages is fundamental to syntax (within linguistics) as well as logic, and these are comfortably accepted as forms of knowledge, notwithstanding the reflective knowledge gains in being forced to make explicit the ontologies for text analysis, which are almost always implicitly presumed in traditional scholarship.
} 
opers from the TEI, which was notable for being an extensible markup system, to the later production of XML (Extensible Markup Language), suggests a process of knowledge production and transmission very much aligned with Mode 2 knowledge production or transdisciplinarity, where even the boundaries of the academy itself, rather than merely the disciplines within them, are exceeded. Many projects within humanities computing, and the digital humanities of today, take this transient form, not only the TEI. Diverse participants briefly commune around a problem, and possibly some funding for the problem, and persist until the project constituted around the problem is completed-and very often the project is associated with building something in an environment where the mind and the hand converge in integrated practice. These participants then split up only to reconstitute around different problems. The Projects Section (DH Commons Projects, [106]) at the DH Commons, an initiative run by the centerNet organization, offers a quite remarkable window into this kind of highly distributed and transient form of knowledge production with the collaborative systems for this now facilitated better than ever before, and across the globe. The resonances with Mode 2 knowledge are salient, and the facility could almost be characterized as one micro-formalization of the Mode 2 knowledge case.

The claim to a correspondence here between the characteristics of humanities computing-type practices and Mode 2 knowledge production and dissemination finds concurrent validation in an issue which we would expect to emerge from these new forms of knowledge output, and this would be the pressures on the career-path and hiring-system practices of the old form; i.e. the career and hiring practices related to tenure in the disciplines, as well as evaluation of, and recognition for, the labor done in the new form. If the sites of knowledge production are heterogeneous and transient, we would expect to find tensions as the new mode of knowledge production finds the traditional faculty-type hiring patterns within the corridors of the academy restrictive, if not asymmetric. This is indeed the case, and the problem is frequently noted. Flanders [107], for example, in an interesting article which uses her own unconventional career path in humanities computing, and later digital humanities, as exemplar, states that many researchers are "located in liminal and academically precarious institutional spaces such as newly created instructional technology support units and grant-funded research groups" (p. 292); and this is of course compared with traditional tenure-type positions in the traditional disciplinary faculties which are stable and associated with linear knowledge production and linear career paths. Work situated in application appears and disappears with the lifetime of each application, and work within humanities computing (and likewise, its heir, digital humanities too) constitute forms of knowledge production which are often not comfortable in the inherited hiring regimes of traditional disciplinary practice.

Bound up with all this is associated pressure on the dominant regime for evaluation of academic contribution. Gibbons et al. [108] deal with the issue of evaluation quite explicitly, noting that the nature of Mode 2 knowledge production places pressures on inherited systems of quality control. In the traditional frameworks of disciplinarity, the systems are fairly well understood. Authorship is either based on the individual, or small groups of individuals, who contribute through their career path in a linear way to the extension and refinement of the discipline, and these contributions, are, by and large, additive and quantifiable, although impact can vary per contribution. With respect to contribution in humanities computing, the picture becomes more fractured for a couple of salient reasons. First, humanities computing projects are often, though not always, projects of scale. They draw on a variety of skills, and authorship becomes complicated and distributed rather than simple and divisible; i.e. a form of socially distributed and socially produced knowledge. Furthermore, the product may not fit nicely into a scholarly journal to be racked up under the prevailing order of research evaluation; although its downstream impact on the ability of traditional scholars to do so might be profound. This is especially so if it is a tool providing new eyes on old problems, or new and refined access to cultural resources in an information-abundant world. Second, the work is often associated with an epistemology of building and service, and hence McCarty's [109] (p. 1224) reference to humanities computing as "collegial service to the disciplines," although it is critical here to point out that this service is not that of a subordinate seconded to technical tasks in support of the real minds in the process. On the contrary, there is mind work or theory involved in, for example, analytically deciding what is scholastically 
present in a text to be described in metalanguage, and then after that only, does the additional technical requirement of actually encoding what is present become required. Stretching the point further, this process is not one-off either, but iterative, as the process of doing raises problems and thus a return to the process of theory, and then back to doing and so on. This service could be characterized as scholarship enhanced rather than scholarship diminished. Ramsay and Rockwell [110] in their work on the epistemology of building use exemplars quite agreeably to illustrate the point:

For this group [humanities computing people or digital humanities people], making their work count is by no means an easy matter. A book with a bibliography is surely scholarship. Is a tool for keeping track of bibliographic data (like Zotero) scholarship? A literary critical article that is full of graphs, maps, and trees is also scholarship (if, perhaps, a little unusual). Is a software framework for generating quantitative data about literary corpora scholarship? A conference presentation about the way maps mediate a society's sense of space is unambiguously an act of scholarship. Is making a map an unambiguous act of scholarship? (p. 76)

All of this suggests forms of practice situated in application which are critical to, and increasingly interwoven with, the disciplines themselves, but which are incompatible with "being seen" by the dominant architectures for research evaluation already in place. These architectures are not necessarily redundant, i.e. they are not simply legacy systems, because the new forms of practice are not there to overwrite the old, but rather to serve or compliment them, and indeed transform with them. The point is that the old system of evaluation is insufficient to the new forms of practice, forms of practice notably resonant with what Gibbons et al. [111] articulate as characteristic of Mode 2 knowledge production.

Closely aligned with the regime of evaluation is the regime of research accountability. Under the traditional framework, the primary context of accountability is the discipline itself with the operational principle being how any given piece of research extends the discipline. Counterpoised, Nicolescu's theorizing would view the academy as, ideally, connected to the world, and not detached from it, and his contributions can be seen as motivated by service to this end. Transdisciplinary knowledge for Nicolescu is knowledge which is as much for the world, as it is about it, and this claim is positioned as critique and advocacy in the face of a perceived inadequacy in knowledge production; and this through a regrettable detachment from the world. Gibbons et al. make a similar point, though from the reverse perspective. Their case is that increasingly knowledge production is so, i.e. as much for the world as about it. They associate this with the emergence of Mode 2 knowledge production which they claim is empirically identifiable, highly situated and configured around problems. And here it would be worth briefly digressing, and going somewhat beyond Gibbons et al., to distinguish problems from problematics. Problematics are the stuff of disciplines, and much of what locates them epistemically as a discipline. However, to be existentially located is a separate issue. Problems are the stuff of Mode 2 knowledge production, and while they existentially locate this new form of knowledge production, as something for the world as much as about it, they don't offer the epistemic location of a problematic and the moorings for disciplinarity. This digression aside, Gibbons et al. identify an enhanced posture of social and public accountability in these Mode 2 knowledge practices, as well as reflexivity to the context of application rather than a disciplinary linearity in spite of, or impervious to, the context of application. Gibbons et al. [112] articulate this property of Mode 2 knowledge largely in the context of scientific practices and the gathering requirement for an enhanced communion with the issues of contemporary humanity, "environment, health, communications, privacy and procreation, and so forth" (p. 7), and therefore revitalized engagement with the knowledge traditionally associated with the humane, and provided by, the humanities. However, the humanities is also singled out by Gibbons et al. for having become detached from this provision, and it is here, precisely, that the discursive shift to the term "digital humanities" and the expanded remit it represents, becomes important with respect to transdisciplinarity. As earlier stated, the lexical transition to the term "digital humanities" (see Note 8), is associated with giving title to the highly influential book $A$ Companion to the Digital Humanities (Unsworth, Schreibman, \& Siemens, [113]), and an effort by Unsworth to prevent the inquiry occurring in humanities comput- 
ing from being seen as exclusively connected with digitization. However, the lexical shift represents far more than a new façade, and digital humanities is more than humanities computing in a new wrapping. Schnapp and Presner [114] see this shift as the divider between the first and second waves of the rise of digital humanities, and Davidson [115] characterizes humanities computing as Humanities 1.0 and digital humanities as Humanities 2.0. Substantively, the lexical shift to the term digital humanities corresponds with an expansion of remit beyond the use of computing and quantitative approaches for the distant reading of text (i.e. the remit of humanities computing) to something much more. This expansion of remit involves two aspects, first, the inversion of the original humanities computing remit is appended to the old remit (Porsdam, [116]), and second, a turn toward visionary discourse emerges (Porsdam, [117]; Svensson, [118], [119]), whereby digital humanities is seen as a contingent stage in the transformation of the humanities in its entirety; i.e. transformation of the epistemology which underpins it, transformation of its interface with the rest of the academy and the public, transformation of the manner in which it produces knowledge and for whom, and so forth.

With respect to the first aspect, the inversion of remit, this essentially refers to the asking of humanitiestype questions of the digital and computation, rather than only bringing the digital and computation to traditional humanities-type questions. For example, Fitzpatrick [120] remarks on how disciplines like rhetoric and composition theorize the difference the computer brings to writing and communication, and this kind of work would now be seen as part of the remit of digital humanities, whereas previously it probably would not have. Similarly, theory on machine/human and digital/human interfaces brings the humane to the nonhumane (e.g. Drucker, [121]; Hayles, [122]; Kirschenbaum, [123]), and not just the other way around. It should be said that this inversion of remit has not always been well received and as early as 2002, when perhaps some of the movements which were to be gathered under the discursive shift to digital humanities were already underway, Unsworth [124] criticized what he perceived as increasing relaxation or permissiveness in the remit for humanities computing to include work which did not involve serious computation. Similarly, and a little later, Hockey [125] (para. 51) characterized the two remits, i.e. the earlier remit of humanities computing and the inverted remit appended to it, as a clash of cultures with the first remit being associated with those who "do it" and the inverted remit with those who "talk about it." Whatever ones position on the merits of these criticisms, it would seem fundamental from the transdisciplinary viewpoint, whether this be from the Nicolescuian approach or the Gibbons et al. approach, that some form of two-way street in terms of dialog between the sciences, computational or otherwise, on the one hand, and the humanities, on the other hand, is necessary for practices, method and theory to emerge which transcend both. In the case of Nicolescuian theorizing, the transfer of methods in one direction only is associated with interdisciplinary practice; i.e. not meeting the threshold or characterization of transdisciplinary practice which operates in a permanent, complimentary and transcendent space with respect to the disciplines. Additionally, Nicolescu's position is theorized in effort to put the humane back into science, as well as to critique and overcome a valuefree science detached from the human condition and detached from the epistemologies associated with the study of the humane. Similarly, Gibbons et al. see new practices rooted in application as connected to the humane for reasons elaborated above, i.e. concerning enhanced postures with respect to social accountability and the public interest; meaning that the agents of knowledge production not only include the gatekeepers of disciplinarity in service to their disciplines, but also include those who are affected by it, via their participation in defining the problems and prioritizing one research direction over another. Thus the addition of the inverted remit associated with the transition to the term "digital humanities," and from whatever transdisciplinary approach one takes, Nicolecuian or Zurich, if not directly manifesting transdisciplinarity, does at least put into place a necessary, but perhaps not sufficient, condition for it.

With respect to the second aspect of the expansion of remit associated with the new term digital humanities, namely, a turn to visionary discourse (Porsdam, [126]; Svensson, [127], [128]), there are some interesting parallels here between the beginnings of the notion of transdisciplinarity in the 1970s, which was arguably associated with visions for transformation of the then academy fed by the disruptive new aspirations located in the counter culture of the 1960s, and the similarly disruptive and vision- 
ary ambitions for digital humanities as a force for transformation of the current academy. These parallels are perhaps less with respect to the theoretical than they are with respect to the zeitgeist, but they are interesting nonetheless, because beneath most change there is a spirit of the times which is often atomized by a discontent of some sort or another. With respect to digital humanities, the rise of visionary discourse reflects heightened ambitions for the forms of inquiry within it. Gone are any thoughts of finding a place alongside the other disciplines, or longing for validation in their eyes; if there ever was any. Instead, a spirit of mission begins to take hold; even a form of exceptionalism. Similarly, and with respect to transdisciplinarity, Bernstein [129], in covering the publication of Toward Transdisciplinary Inquiry in the Humane Sciences by a young American postgraduate, Jack Lee Mahan ${ }^{10}$, remarks on the optimistic origins of transdisciplinarity in these early times. This optimism was, he says, rooted in "the possibility for a new synthesis in higher education technology, and science" (para. 3). He goes on to locate this optimism in the fact that funding after the Apollo program in the sciences ripened the context "for thinking big and imagining what the university could be in a perfect world" (para. 3), and also in the fact that generational conflict in the counterculture had left lingering "utopian speculation about the future possibilities for universities" (para 4). Of course, as Bernstein argues, the oil shocks of the 1970s and concomitant withdrawal of generous funding arrested some of these aspirations and the associated trajectories of, or desires for, change. This led to the period of quiet with respect to transdisciplinarity before its reprise through the work of scholars such as Nicolescu [130], [131], [132], [133] and Gibbons et al. [134] among others. With respect to the digital humanities, Svensson [135] argues for it being a project during a period of substantial transformation in the academy, and in a later article of the same year (Svensson, [136]) he argues that "the field has come to constitute a site for far-reaching discussions about the future of the field itself as well

\footnotetext{
${ }^{10}$ The publication Toward Transdisciplinary Inquiry in the Humane Sciences by Jack Lee Mahan (Doctoral Dissertation, UMI No. 702145) was extraordinarily contemporaneous with, but independent of, similar publications by leading figures. This would include a paper entitled "Inter- and transdisciplinary university: A systems approach to education and innovation," and published in the journal Higher Education in 1972 (Volume 1, pp. 7-37) by E. Jantsch.
}

as the humanities at large" (para. 1). Thinking big and reimagining the academy are now firmly part of the rhetorical and aspirational positioning of an important section of digital humanities adherents. In one of the 2012 papers, Svensson [137] points out that visionary discourse is often associated with technological transformation, and though he does not say this, we can presume such discourse to be driven by the collective envisioning of the possibilities and implications of new digital technologies. He adds that the new forms of work associated with digital humanities test existing structures and traditions, and that this is one of the attractions for people who happen to already be interested in the transformation of the humanities. Thus we could summarize this position by saying that the disruptive potential of digital humanities attracts people who see value in disruption; with this value being catalyst for change.

One of the sources which Svensson uses to articulate this visionary outlook within significant constituencies of digital humanities is the Digital Humanities Manifesto 2.0 (Schnapp \& Presner, [138]). This manifesto is offered very much in the disruptive rhetoric of hacktivism which increasingly appears to be one discourse component of some of the "reimagining of the academy," and while this particular, and more recent, form of activist rhetoric is not identical to the rhetoric of the counter culture of the 1960s, it is notable that the manifesto explicitly declares lineage to this:

Digital [h] umanities have a utopian core shaped by its genealogical descent from the counterculture-cyberculture intertwinglings of the $60 \mathrm{~s}$ and $70 \mathrm{~s}$. This is why it affirms the value of the open, the infinite, the expansive, the university/museum/archive/library without walls, the democratization of culture and scholarship, even as it affirms the value of large-scale statistically grounded methods (such as cultural analytics) that collapse the boundaries between the humanities and the social and natural sciences. (para. 13)

The democratization of scholarship referred to here is tied up with contemporary issues such as open access and copyright, but also is related to advocacy for a new union between expert and the wider public, eschewing the rarified specializations, with their associated authority, which occupy the corridors of the academy and offices of the disciplines, putting 
them in isolation from each other and from the wider human space. Schnapp and Presner state that "the demand for ever increasing degrees of specialization must be placed under constant pressure by the need for transversal, transdisciplinary, innovative thinking" (para. 22). There are strong associations here with both the Nicolesuian and Zurich schools, although with some analytical separation necessary. Nicolescu [139] tends to talk of integrative and generative practices for complex problems, and we certainly see advocacy for both integration and generation in the manifesto, but while Nicolescu's jump-off point is the problem of complexity, the manifesto, and indeed much other work in digital humanities, has the problem of information abundance (see Rosenzweig [140]) as its jump-off point. But the resonances are there, and certainly Nicolescu's approach would advocate the academy as intimately connected to the wider world rather than splendidly isolated from it. From the approach of the Zurich school, what is particularly notable is the practice-rooted discourse of the manifesto and its dissociation from Mode 1 forms of knowledge production. For example, the authors state "[m]odern scientific models of scholarship have prided themselves on the equation between rigor and the affect-neutral relaying of disembodied information" [141] (para. 25), and the authors place digital humanities knowledge production in juxtaposition to this. Knowledge produced in the context of application, or Mode 2 knowledge, is also precisely not this; i.e. not disembodied. The embodied nature of Mode 2 knowledge is in fact its signature characteristic. Mode 2 knowledge represents an existential warrant, not at the exclusion of the epistemic, but perhaps, and more subtly, not defined by it. What is not clear in this quote, however, is the exact nature of the stated equation between rigor and disembodied information, and being from a manifesto designed to be brief and declarative rather than studious and elaborated, it will remain unclear. This is important, because in terms of transdisciplinarity, neither theoretical school would want to emphasize embodied knowledge at the expense of rigor. Both schools would see this as a false equation, and it is perhaps here that a more comprehensive engagement between digital humanities and theorized transdisciplinarity has critical value.

Overall, and in view of the above, it is quite arguable that the lexical transition to the term "digital humanities," and the expansion of remit it signifies over the previous and more focused remit for humanities computing, involves change which puts digital humanities into an increasingly ergonomic posture with respect to transdisciplinarity; though we need to remain critically alert in this understanding. The following positions, if not defensible in view of the analysis conducted above, are at least worthy of further consideration and assessment. In terms of the definitional articulations of the three forms of supradisciplinary activity, and while these usually offer far less analytical power than the work of the theorists, it would be reasonable to say that humanities computing and digital humanities generally exceeds multidisciplinarity, which is the least contested form of supradisciplinary activity. It would also be fair to say that interdisciplinarity and transdisciplinarity present a more muddled picture with respect to their distinction, in terms of the definitions, and it is more difficult to negotiate a position on humanities computing or digital humanities being either one of these. This insufficiency and lack of clarity is not at all so evident, however, if we turn to more elaborated theoretical contributions; i.e. the contributions of Nicolescu [142], [143], [144], [145] and Gibbons et al. [146]. Here the following conclusions appear to be tenable. Humanities computing in terms of the Nicolescuian approach evidences very strong correspondences with the theorization of interdisciplinary practice, and specifically with regard to the degrees of application and epistemology. In terms of the degree of generation of new disciplines, however, the resistance of humanities computing, over many years, to becoming institutionalized within the disciplinarities is notable, and is potentially evidence of this area of inquiry having transdisciplinary properties or tendencies; properties and tendencies which are persistent, if not amplified, by the expansion of remit associated with the lexical transition to the term "digital humanities." In terms of Gibbons et al. and the Zurich approach, where application constitutes the primary site for transdisciplinary or Mode 2 knowledge production, humanities computing resonates strongly with transdisciplinarity, and the expansion of remit associated with digital humanities, again, amplifies this resonance because exchange of methods, epistemologies and so forth become more reciprocal. Finally, and although not a theoretical issue, the correspondence between the envisioning of transformation of the academy by digital humanities and similar envisioning in the early life 
of transdisciplinarity is quite arresting, and should invite further and more particularized inquiry.

\section{Conclusion}

Putting the three forms of activity which go beyond disciplinary bounds into critical and analytical engagement with digital humanities, and with its predecessor, humanities computing, was intended to offer some return, even if only preliminary and excursive, on the following question. Do the three forms of supradisciplinary activity and digital humanities serve each other in some way, or even comprise shared expressions of the same, or similar, phenomenon? In view of the discussion above, and at a very general level, critique of disciplinarity is obviously central to the mission of transdisciplinarity, and though digital humanities is visibly concerned with bringing computing and the digital to the humanities, and the other way around, another remarkable implication, or even exigency, of its practices is critique of disciplinarity. This lends to a view that supradisciplinarity and digital humanities are objective allies of a sort, even if this has been far too implicit and, perhaps more importantly, far too undertheorized to date. More specifically, however it would also seem apparent that multidisciplinarity does not offer much as a site for further substantive inquiry into the posture that digital humanities has with respect to supradisciplinary practice, because digital humanities clearly exceeds this form The analytically consequential discussion for digital humanities centers on interdisciplinarity and transdisciplinarity, and one would have to conclude that pursuit of this discussion would have to at least start from a Nicolescuian framework, because the Zurich school does not offer extended theorization of interdisciplinarity vis-à-vis transdisciplinarity. It offers an elaborated case for transdisciplinarity as a free-standing concept via explication of Mode 2 knowledge production, but it is largely left to the Nicolescuian framework to explicate transdisciplinarity as theoretically adjacent to other expressions of supradisciplinary practice such as interdisciplinarity.

Most vital in view of the above discussion, however, is the case that digital humanities represents one instantiation of a deeper turn to interdisciplinary inquiry on the lower horizon and transdisciplinarity on the upper horizon, and across the knowledge production spectrum. In other words, digital human- ities, which is quite self-aware as a rising force within the humanities and the academy, is historically situated within a trajectory which adds up to more than itself. A relative lack of situational awareness in this respect, notwithstanding the self-awareness, is arguably associated with the lack of purposeful theorization of digital humanities with respect to the three different forms of supradisciplinary practices, and this despite the casual claims to being connected with such practices.

Digital humanities associates itself with transformation, and transformation usually comes with exhilaration and consternation in somewhat equal measure, and in this context the posture of digital humanities towards the disciplines themselves, as well as visions for the transformation of the academy, will remain an ongoing issue. These issues should be approached with caution, but not ducked, and above all should receive theoretical treatment. All arguments for digital humanities and its vital role in a changing academy are better made if its place in the knowledge ecology with which it is associated profits from theorization; and supradisciplinary activity presents as a critically important site for this theorization. A more theoretical and sustained dialog between digital humanities and different expressions of supradisciplinary activity can certainly assist digital humanities in representing itself. Theorization is the means to ensuring that disruption is more than a mere disturbance of the order, and rather the potential for creative change to ultimately reach mature expression. In other respects too, and at least from the pedagogical point of view which is not covered in this paper, theorization is an important mooring for negotiating the change with which digital humanities is associated. There are important questions around the continuing worth of disciplinarity as part of the necessary training of mind, and theorization of digital humanities with respect to disciplinary and supradisciplinary practice is important and stabilizing here too. It is one thing to discard boundaries one is aware of in acts of conscious transcendence, and another to be, or to become, unwitting of them. There is a visionary discourse emerging within digital humanities, and while this is quite arguably to be welcomed, a more rigorous and persistently theorized conversation between digital humanities and the three expressions of going beyond disciplinary bounds, including multidisciplinarity and interdisciplinarity, but focusing on transdisciplinarity, may 
help to situate, critique and ground these visions. This in turn allows us to proceed beyond the spirit of the times, and into a more explicit and formal articulation of the broader knowledge condition, and the place of digital humanities in it.

\section{Acknowledgment}

I would like to thank Rolf Gaede (Associate Professor at Durban University of Technology, South Africa) for helpful comments on a developing version of this paper, and enjoyable conversations around some of these issues. I would also like to thank Durban University of Technology which hosted the sabbatical on which some of the conception for the paper was formed and elaborated.

Funding: This research received no external funding.

Conflicts of Interest: The author declare no conflict of interest.

\section{References}

[1] centerNet (2017). An international network of digital humanities centers. Retrieved from http://www.dhcenternet.org/

[2] Schreibman, S., Siemens, R., \& Unsworth, J. (Eds.). (2004). A companion to digital humanities. Oxford: Blackwell.

[3] Svensson, P. (2009). Humanities computing as digital humanities. Digital $\mathrm{Hu}$ manities Quarterly, 3(3). Retrieved from http://www.digitalhumanities.org/dhq/vol/3/3/ 000065/000065.html

[4] Hockey, S. (2004). The history of humanities computing. In S. Schreibman, R. Siemens \& J. Unsworth (Eds.), A companion to Digital Humanities (pp. 319). Oxford: Blackwell.

[5] Porsdam, H. (2011). Too much 'digital', too little 'humanities'? An attempt to explain why many humanities scholars are reluctant converts to digital humanities. The Arcadia series of seminars and lectures, Cambridge University, (2011). Retrieved from http://arcadiaproject.lib.cam.ac.uk/docs/Digital Humanities.pdf

[6] Svensson, P. (2012). The digital humanities as a humanities project. Arts and Humanities in Higher Education, 11(1-2), 42-60.

[7] Svensson, P. (2012). Envisioning the digital humanities. Digital Humanities Quarterly, 6(1). Retrieved from http:www.digitalhumanities.org/dhq/vol/6/1/ 000112/000112.html
[8] Schnapp, J. \& Presner, P. (2009). Digital Humanities Manifesto 2.0. Retrieved from http://manifesto.humanities.ucla.edu/2009/05/29/ the-digital-humanities-manifesto-20/

[9] Svensson, P. (2012). Beyond the big tent. In M. K. Gold (Ed.), Debates in the digital humanities (pp. 36-49). Minneapolis: University of Minnesota Press.

[10] Nicolescu, B. (2002). Manifesto of transdisciplinarity. Translation: Karen-Claire Voss. Albany, NY: SUNY Press.

[11] Nicolescu, B. (2005). Towards transdisciplinary education. TD: The Journal for Transdisciplinary Research in Southern Africa, 1(1), 5-16.

[12] Nicolescu, B. (2006). Transdisciplinarity: Past, present and future. In B. Haverkort \& C. Reijntjes (Eds.), Moving worldviews - Reshaping sciences, policies and practices for endogenous sustainable development (pp. 142-166). Leusden, Netherlands: COMPAS Editions.

[13] Nicolescu, B. (2010). Methodology of transdisciplinarity: Levels of reality, logic of the included middle and complexity. Transdisciplinary Journal of Engineering and Science, 1(1), 19-38.

[14] Gibbons, M., Limoges, C., Nowotny, H., Schwartzman, S., Scott, P., \& Trow, M. (1994). The new production of knowledge: The dynamics of science and research in contemporary societies. London: Sage.

[15] Gibbons, M. et al. (1994). op. cit.

[16] Klein, J. T. (2006). Afterword: the emergent literature on interdisciplinary and transdisciplinary research evaluation. Research Evaluation, 15, 75-80.

[17] Klein, J. T. (2008). Evaluation of interdisciplinary and transdisciplinary research: A literature review. American Journal of Preventive Medicine, 35(2), 116-123.

[18] Spaapen, J., Dijstelbloem, H., \& Wamlink, F. (Eds.). (2007). Evaluating research in context: a method for assessment (2nd ed.). The Hague, Netherlands: Consultative Committee of Sector Councils for Research and Development.

[19] Rosenfeld, P. L. (1992). The potential of transdisciplinary research for sustaining and extending linkages between the health and social sciences. Social Science and Medicine, 35(11), 1343-1357.

[20] Choi, B. C. K., \& Pak, A. W. P. (2006). Multidisciplinarity, interdisciplinarity and transdisciplinarity in health research, services, education and policy: 1. Definitions, objectives, and evidence of effectiveness. Clinical and Investigative Medicine, 29(6), 351-364.

[21] Nicolescu, B. (2002). op. cit.

[22] Nicolescu, B. (2005). op. cit.

[23] Nicolescu, B. (2006). op. cit.

[24] Nicolescu, B. (2010). op. cit.

[25] Gibbons, M. et al. (1994). op. cit.

[26] McGregor, S. L. T. (2014). TDMeme: A 
transdisciplinary meme. Integral Leadership Review, 14(2). Retrieved from http://integralleadershipreview.com/11271331-transdisciplinary-meme/

[27] McGregor, S. L. T. (2015). Transdisciplinary knowledge creation. In P. T. Gibbs (Ed.), Transdisciplinary professional learning and practice (pp. 9-24). New York: Springer.

[28] Klein, J. T. (2004). Prospects for transdisciplinarity. Futures, 36, 515-526.

[29] Rosenfeld, P. L. (1992). op. cit.

[30] Choi, B. C. K., \& Pak, A. W. P. (2006). op. cit.

[31] Choi, B. C. K., \& Pak, A. W. P. (2006). op. cit.

[32] Choi, B. C. K., \& Pak, A. W. P. (2006). op. cit.

[33] Choi, B. C. K., \& Pak, A. W. P. (2006). op. cit.

[34] Rosenfeld, P. L. (1992). op. cit.

[35] Nicolescu, B. (2005). op. cit.

[36] Rosenfeld, P. L. (1992). op. cit.

[37] Nicolescu, B. (2005). op. cit.

[38] Kessler, D. (1999). Transdisciplinary approach to pediatric undernutrition. Developmental Behavioral News, 8. Retrieved from http://www.dbpeds.org/section/

[39] Common, M., \& Stagl, S. (2005). Ecological economics: An introduction. Cambridge: Cambridge University Press.

[40] Flinterman, J. F., Teclemariam-Mesbah, R., Broerse, J. E. W., \& Bunders, J. F. G. (2001). Transdisciplinary: the new challenge for biomedical research. Bulletin of Science, Technology and Society, 21(4), 253-266.

[41] Tress, B., Tress, G., \& Fry, G. (2005). Researchers' experiences, positive and negative, in integrative landscape projects. Environmental Management, 36(6), 792-807.

[42] Gibbons, M. et al. (1994). op. cit.

[43] Choi, B. C. K., \& Pak, A. W. P. (2006). op. cit.

[44] NSERC, Natural Sciences and Engineering Research Council of Canada (2004). Guidelines for the preparation and review of applications in interdisciplinary research. Ottawa: NSERC.

[45] CIHR, Canadian Institutes of Health Research (2005). Training program grant guide: Strategic training initiative in health research. Ottawa: CIHR.

[46] Soskolne, C. (2000). Transdisciplinary approaches for public health. Epidemiology, 11(4), S122.

[47] Rosenfeld, P. L. (1992). op. cit.

[48] Rosenfeld, P. L. (1992). op. cit.

[49] Choi, B. C. K., \& Pak, A. W. P. (2006). op. cit.

[50] Nicolescu, B. (2002). op. cit.

[51] Nicolescu, B. (2005). op. cit.

[52] Nicolescu, B. (2006). op. cit.

[53] Nicolescu, B. (2010). op. cit.
[54] Nicolescu, B. (2005). op. cit.

[55] Nicolescu, B. (2005). op. cit.

[56] Nicolescu, B. (2002). op. cit.

[57] Nicolescu, B. (2005). op. cit.

[58] Nicolescu, B. (2010). op. cit.

[59] Nicolescu, B. (2010). op. cit.

[60] Gibbons, M. et al. (1994). op. cit.

[61] Gibbons, M. et al. (1994). op. cit.

[62] Gibbons, M. et al. (1994). op. cit.

[63] Bernstein, J. H. (2015). Transdisciplinarity: A review of its origins, development, and current issues. Journal of Research Practice, 11(1). Retrieved from http://jrp.icaap.org/index.php/jrp/article/view/510 $/ 412$

[64] Gibbons, M. et al. (1994). op. cit.

[65] Nicolescu, B. (2006). op. cit.

[66] Choi, B. C. K., \& Pak, A. W. P. (2006). op. cit.

[67] Choi, B. C. K., \& Pak, A. W. P. (2006). op. cit.

[68] Rosenfeld, P. L. (1992). op. cit.

[69] Nicolescu, B. (2005). op. cit.

[70] Choi, B. C. K., \& Pak, A. W. P. (2006). op. cit.

[71] Rosenfeld, P. L. (1992). op. cit.

[72] Kirschenbaum, M. (2012). What is digital humanities and what's it doing in English departments? In M.K. Gold (Ed.), Debates in the digital humanities (pp. 3-11). Minneapolis: University of Minnesota Press.

[73] Hockey, S. (2004). op. cit.

[74] Svensson, P. (2009). op. cit.

[75] Hockey, S. (2004). op. cit.

[76] Fitzpatrick, K. (2012). The humanities done digitally. In M. K. Gold (Ed.), Debates in the digital humanities (pp. 12-15). Minneapolis: University of Minnesota Press.

[77] Hockey, S. (2004). op. cit.

[78] Burnard, L. (1988). Report of workshop on text encoding guidelines. Literary and Linguistic Computing, 3(2), 131-133.

[79] Hockey, S. (2004). op. cit.

[80] TEI Consortium (2015). TEI P5: Guidelines for electronic text encoding and interchange. [2.8.0]. [2015, April 6]. TEI Consortium. Retrieved from http://www.tei-c.org/Guidelines/P5/

[81] Burdick, A., Drucker, J., Lunenfeld, P., Presner, T., \& Schnapp, J. (2012). Digital Humanities. Cambridge: MIT Press.

[82] Schnapp, J. \& Presner, P. (2009). op. cit.

[83] Moretti, F. (2007). Graphs, maps, trees: Abstract models for a literary history. London: Verso.

[84] McCarty, W. (2012). A telescope for the mind? In M. K. Gold (Ed.), Debates in the digital humanities (pp. 113-123). Minneapolis: University of Minnesota Press. 
[85] Choi, B. C. K., \& Pak, A. W. P. (2006). op. cit.

[86] Choi, B. C. K., \& Pak, A. W. P. (2006). op. cit.

[87] Soskolne, C. (2000). op. cit.

[88] Nicolescu, B. (2005). op. cit.

[89] Craig, H. (2004). Stylistic analysis and authorship studies. In S. Schreibman, R. Siemens \& J. Unsworth (Eds.), A companion to Digital Humanities (pp. 273288). Oxford: Blackwell.

[90] Hockey, S. (2004). op. cit.

[91] McCarty, W. (2003). Humanities computing. Encyclopedia of Library and Information Science, 12241236.

[92] McCarty, W. (2003). op. cit.

[93] Nicolescu, B. (2005). op. cit.

[94] Nicolescu, B. (2010). op. cit.

[95] Burnard, L. (1999). Is Humanities Computing an Academic Discipline? or, Why Humanities Computing Matters [HTML]. Position statement for interdisciplinary seminar titled "Is Humanities Computing an Academic Discipline?" (1999). Retrieved from the Institute of Advanced Technology in the Humanities, University of Virginia, http://www.iath.virginia.edu/hcs/burnard.html

[96] McCarty, W. (2003). op. cit.

[97] Schnapp, J. \& Presner, P. (2009). op. cit.

[98] Svensson, P. (2012). The digital humanities as a humanities project. op. cit.

[99] Svensson, P. (2012). Envisioning the digital humanities. op. cit.

[100] Gibbons, M. et al. (1994). op. cit.

[101] Ramsay, S., \& Rockwell, G. (2012). Developing things: Notes toward an epistemology of building in the digital humanities. In M. K. Gold (Ed.), Debates in the digital humanities (pp. 75-84). Minneapolis: University of Minnesota Press.

[102] Gibbons, M. et al. (1994). op. cit.

[103] McCarty, W. (2003). op. cit.

[104] Gibbons, M. et al. (1994). op. cit.

[105] Gibbons, M. et al. (1994). op. cit.

[106] DH Commons Projects (2015). Projects. Retrieved from http://dhcommons.org/projects

[107] Flanders, J. (2012). Time, labor, and "alternate careers" in digital humanities. In M. K. Gold (Ed.), Debates in the digital humanities (pp. 292-308). Minneapolis: University of Minnesota Press.

[108] Gibbons, M. et al. (1994). op. cit.

[109] McCarty, W. (2003). op. cit.

[110] Ramsay, S., \& Rockwell, G. (2012). op. cit.

[111] Gibbons, M. et al. (1994). op. cit.

[112] Gibbons, M. et al. (1994). op. cit.

[113] Unsworth, J., Schreibman, S., \& Siemens, R. (Eds.). (2004). A companion to the digital humanities. Oxford: Blackwell.
[114] Schnapp, J. \& Presner, P. (2009). op. cit.

[115] Davidson, C. N. (2008). Humanities 2.0: Promise, Perils, Predictions. Publications of the Modern Language Association of America (PMLA), 123(3), 707717.

[116] Porsdam, H. (2011). op. cit.

[117] Porsdam, H. (2011). op. cit.

[118] Svensson, P. (2012). The digital humanities as a humanities project. op. cit.

[119] Svensson, P. (2012). Envisioning the digital humanities. op. cit.

[120] Fitzpatrick, K. (2012). op. cit.

[121] Drucker, J. (2013). Performative materiality and theoretical approaches to interface. Digital Humanities Quarterly, 7(1). Retrieved from http://www.digitalhumanities.org/dhq/vol/7/1/ 000143/000143.html

[122] Hayles, N. K. (2008). Electronic literature: New horizons for the literary. Notre Dame, Indiana: University of Notre Dame.

[123] Kirschenbaum, M. (2012). op. cit.

[124] Unsworth, J. (2002). What is humanities computing and what is not? Illinois Informatics Institute, University of Illinois, Urbana. Retrieved from http://computerphilologie.unimuenchen.de/jg02/unsworth.html

[125] Hockey, S. (2004). op. cit.

[126] Porsdam, H. (2011). op. cit.

[127] Svensson, P. (2012). The digital humanities as a humanities project. op. cit.

[128] Svensson, P. (2012). Envisioning the digital humanities. op. cit.

[129] Bernstein, J. H. (2015). op. cit.

[130] Nicolescu, B. (2002). op. cit.

[131] Nicolescu, B. (2005). op. cit.

[132] Nicolescu, B. (2006). op. cit.

[133] Nicolescu, B. (2010). op. cit.

[134] Gibbons, M. et al. (1994). op. cit.

[135] Svensson, P. (2012). The digital humanities as a humanities project. op. cit.

[136] Svensson, P. (2012). Envisioning the digital humanities. op. cit.

[137] Svensson, P. (2012). The digital humanities as a humanities project. op. cit.

[138] Schnapp, J. \& Presner, P. (2009). op. cit.

[139] Nicolescu, B. (2002). op. cit.

[140] Rosenzweig, R. (2003). Scarcity or abundance: Preserving the past in a digital era. American Historical Review, 108 (3), 735-762.

[141] Schnapp, J. \& Presner, P. (2009). op. cit.

[142] Nicolescu, B. (2002). op. cit.

[143] Nicolescu, B. (2005). op. cit.

[144] Nicolescu, B. (2006). op. cit. 
[145] Nicolescu, B. (2010). op. cit.

[146] Gibbons, M. et al. (1994). op. cit.

\section{About the Author}

Ian Isemonger is an Associate Professor in the Faculty of Letters, Kumamoto University, Japan. At the undergraduate level, he teaches in the Department of Communication and Information. At the postgraduate level, he teaches and supervises for the Graduate School of Social and Cultural Sciences on the master's and doctoral degree programs in English education, and has taught curriculum design, second language acquisition theory (a subfield of psycholinguistics), statistics, and psychometrics. In the climate of change in tertiary education in Japan, he has more recently developed an interest in digital humanities and its association with new forms of knowledge-production, such as those covered in this paper. 